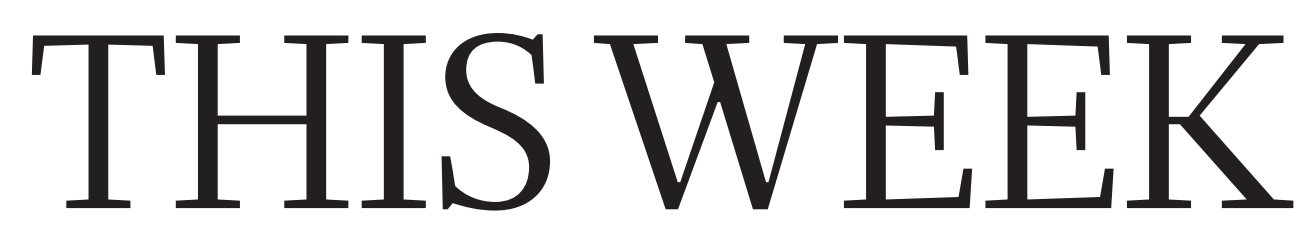

EDITORIALS

SPIDERS The amazing webs and weaving of our eight-legged friends $\mathbf{p . 6}$
WORLD VIEW The row over the Global Fund could spell disaster $\mathbf{p . 7}$
ILLUSION Perceived

brightness is in the eye of the beholder $\mathbf{p . 8}$

\title{
The low-level nuclear threat
}

\author{
Europe is making a good start on learning about the health risks of low-dose radiation with a \\ programme to share cold-war data and set research priorities. But the effort needs to be global.
}

$\mathrm{F}$ ear of the effects of an atomic strike haunted the politicians and scientists of the cold war. For years, researchers around the world worked on massive and systematic programmes to understand how ionizing radiation might affect survivors of a blast. Almost half a billion animals in the United States, the Soviet Union, Europe and Japan - mostly rats and mice, but also thousands of dogs and some rabbits and monkeys - were deliberately irradiated. These experiments were well designed and worked to identify the pathological consequences of doses of various types of radiation, delivered at different rates and by different routes, including inhalation or ingestion. Results were documented in detail and tissue samples were kept.

The political thaw of 1989 changed priorities, and these experiments and their results were largely forgotten. So were the scientists. But concern about ionizing radiation didn't fade entirely: instead, it was transferred increasingly to worries about low-level occupational exposure in the nuclear (and other) industries, and about exposure during medical diagnosis and treatment. The meltdown of the nuclear reactor in Chernobyl, now in Ukraine, in 1986 gave rise to new concern and political pressure, which was exacerbated by the Fukushima accident in Japan last year.

Science hasn't yet provided all the answers that governments need to respond to these concerns. Epidemiological studies, backed by animal experiments, have established beyond doubt that exposure to radiation levels above 100 millisieverts increases the risk of cancer in a predictable, dose-dependent way. But the risk to health at lower exposure levels is harder to pin down. In Germany, for example, the dose limit for occupational exposure is 20 millisieverts per year. But even when this limit is respected, there are more than 70,000 reports of suspected health damage among exposed workers each year, more than double the number in 1960. Some epidemiological studies suggest that low doses of radiation - as few as 10 millisieverts in children - may increase cancer risk in susceptible individuals, and may be associated with other conditions, such as heart disease and stroke. People living close to Fukushima are anticipated to receive around 10 millisieverts of accumulated radiation exposure each over the next decade.

Radiation-protection agencies want to check whether the weak associations between low-dose radiation and diseases are real. If they are, agencies need to understand the biological mechanisms behind them.

In 2008, the German Federal Office for Radiation Protection led an initiative with agencies from four other European countries and the European Commission to sketch out a rational, systematic plan to crack the low-dose problem. Their report was published in January 2009. It spawned the Multidisciplinary European Low Dose Initiative (MELODI), a platform of 15 European agencies and institutes that will develop and coordinate scientific policies. It also produced a 6-year, $€ 13$-million (US\$17.2-million) European Commission Network of Excellence to help to set up the platform and address some of its questions. Keen to maintain the musical theme, the network calls itself Low

Dose Research Towards Multidisciplinary Integration, or DoReMi.

Epidemiology has an important role in radiation research, but only when the dose received by an individual can be calculated with confidence, as in medical exposure. There must also be research on animals, posing questions not so different from those asked by radiobiologists during the cold war. Modern scientists won't be able to do animal

"Agencies want to check whether the associations between lowdose radiation and diseases are real." tion-protection agencies and research institutes around the world who have taken up the challenge of low-dose radiation research met to discuss how to share contemporary information, and how to make the vast archives of historical data available to all.

It will involve a mammoth digitization and curation effort - expensive even before new experiments to plug gaps are factored in. Some members of MELODI estimate that it could cost up to $€ 1$ billion to understand the full biological effects of low-dose radiation. Yet the problem needs more than just money: it needs lobbying to attract biologists from other disciplines, who tend to dismiss radiobiology as old-fashioned.

MELODI has made a fine start on structuring a European scientific approach to a serious social problem. It now needs to orchestrate itself as a global platform — an unchained MELODI, if you like.

\section{Poles apart}

Protecting the Arctic from pollution requires a binding agreement like the Antarctic Treaty.

$\mathrm{L}$ ast month's centenary of the ill-fated arrival of Robert Scott at the South Pole prompted a swell of events and publicity. Yet there is another noteworthy anniversary from the far south this month. Sixty years ago, Antarctica - perhaps for the first and only time echoed to the sound of hostile gunfire. In what became known as the 1952 Hope Bay Incident, Argentinian soldiers fired a machine gun over the heads of a British landing party that was attempting to re-establish and supply an Antarctic base that had burnt down several years earlier. In response, the British despatched armed marines from the Falkland Islands, who forced the Argentinians to retreat 